\title{
A THIN CELL FOR USE IN DETERMINING THE REFRACTIVE INDICES OF CRYSTAL GRAINS
}

\author{
By Charles Proffer Saylor
}

\section{ABSTRACT}

The use of those immersion methods for determining refractive index in which a regulation of temperature is employed has been seriously limited by the impossibility of obtaining interference figures. A thin cell is described which overcomes this obstacle, so that it is possible to know the exact orientation of the crystal grains which are chosen for identification.

A distinct impediment in applying the double-variation method of Emmons ${ }^{1}$ for determining refractive indices has been the impossibility of obtaining conoscopic interference figures. As it is only in special cases, therefore, that the optical orientation of a crystal grain can be accurately known, the peculiar advantages of the method are almost lost. Emmons endeavors to remedy this situation in a later publication, ${ }^{2}$ in which he describes an application of the universal stage to the problem, but this method is cumbersome and slow, and a large proportion of particles are too small to be studied with it. ${ }^{3}$

Emmons mounts the preparation upon a cell with glass windows, between which water of controlled temperature is circulated. The temperature of the liquid mounting of the crystal fragments quickly becomes almost the same as that of the water. The refractive index of the liquid is modified accordingly and can be made to match an index of the immersed crystal fragments. But this cell is so thick that the preparation is raised above the region traversed by the more oblique rays. Consequently, satisfactory interference figures are impossible. To avoid this difficulty, the writer, three years ago, constructed a cell of different form. It has been successful, and during three years of use no reason has appeared for modifying the design shown in figure 1.

Three pieces of brass A, B, and $\mathrm{C}$, which are $0.5,0.9$, and $0.2 \mathrm{~mm}$ thick, respectively, were cut along the full lines with a jeweler's jig saw. Two holes were drilled in A, as shown. From B, clamped upon a plane surface, half the thickness of the parts indicated by stippling was removed with a chisel, and, in the same manner but from the reverse side, half the thickness was removed from those parts indicated by crosshatching. The bottom of $\mathrm{A}$, the top and bottom of $\mathrm{B}$, and the top of $\mathrm{C}$ were thinly coated with solder; the

\footnotetext{
1 R. C. Emmons, Am. Mineral. 13, 504 (1928); 14, 414 (1929)

2 A. N. Winchell, The Microscopic Characters of Artificial Inorganic Solid Substances or Artificial Minerals, (John Wiley \& Sons, Inc., 1931). Chapter VIII, on the Universal Stage, was written by Emmons. ${ }_{3}$ These difficulties are clearly set forth in a review of Winchell's book by G. Tunell and G. W. Morey, J. Am. Chem. Soc. 54, 2574-7 (1932).
} 

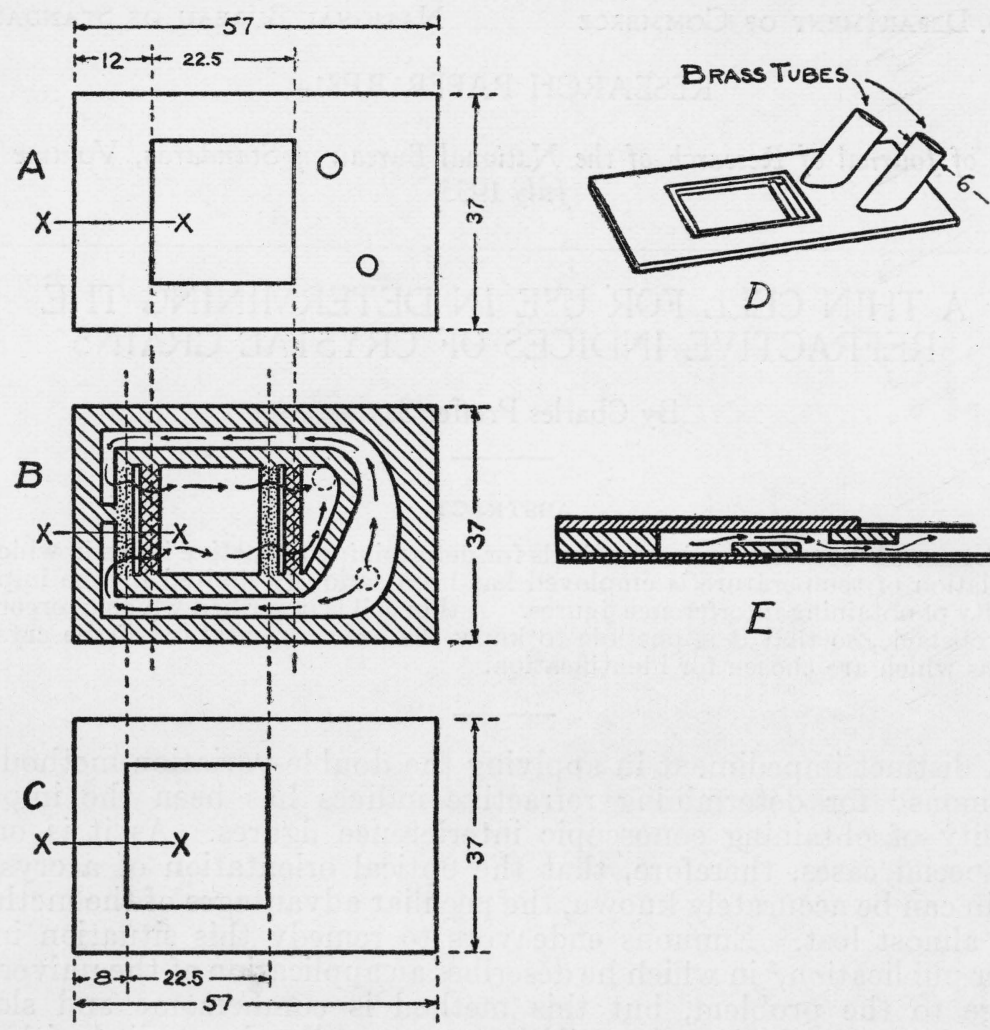

FiguRe 1.-Details of the cell.

$\mathrm{A}, \mathrm{B}$, and $\mathrm{C}$ are three-fifths their actual size. E, taken along the line $\mathrm{xx}$, is four times the scale of $\mathrm{A}, \mathrm{B}$, and $\mathrm{C}$. All dimensions are given in millimeters.

three pieces were superimposed and sweated together. The solder which extruded around the edges of the brass plates and the window was removed, and the edges were smoothed. The two short pieces of brass tubing indicated in $\mathrm{D}$, each with a bevelled end, were soldered over the holes in A. Square cover glasses (no. $2 ; 22 \mathrm{~mm}$ ) were cemented in the recesses ${ }^{4}$ which were provided, top and bottom, by the shapes of the pieces A, B, and C. A perspective drawing of the completed cell is shown in figure 1 (D), and in figure 1 (E) a section along the dotted line $\mathrm{xx}$ is shown. The metal parts are hatched.

The apparatus is satisfactorily durable despite the thinness of the cover glasses. Cementing along the four edges lends much strength, and the cover glasses have never been accidentally broken. In the completed cell the distance from the bottom of the lower cover glass to the top of the upper one is $1.35 \mathrm{~mm}$. The thickness of the cell, therefore, is about the same as that of an average microscope slide, and it is used like one. There is no difficulty in obtaining interference figures or controlling the temperature with all desirable accuracy.

- Of various cements tried, only Schaar \& Company's Cementyte D proved satisfactory. The others loosened when very hot water was circulated through the cell.

Washington, April 30, 1935. 